\title{
Translation into Brazilian portuguese, cultural adaptation and validation of the oral health impact profile (ohip-49)
}

\section{Tradução para a língua portuguesa, adaptação cultural e validação do "oral health impact profile" (ohip-49)}

\author{
Cássia Pérola dos Anjos Braga Pires* \\ Marcos Bosi Ferraz** \\ Mauro Henrique Nogueira Guimarães de Abreu***
}

\begin{abstract}
The aim of this study is to develop a Portuguese version of the OHIP-49 to be used in Brazil. The adopted methodology involves translation, back-translation, revision of the first version, cultural adaptation and evaluation of its measurement properties. The questionnaire was administered in interviews with 60 year-old and older Brazilian people. The Kendall-tau correlation coefficient was used to assess reproducibility; the Cronbach $\alpha$ coefficient was used to verify internal consistency and the Kruskal-Wallis and Mann-Whitney U tests were used to assess validity. Reproducibility was shown to be statistically significant, with coefficients ranging from 0.72 to 0.74 between dimensions of three interviews. The Cronbach $\alpha$ coefficients were 0.96 and 0.90 respectively for the dimensions of the interviews and for total items. Constructive validity, demonstrated through a comparison between the questionnaire dimensions and the clinical parameters, showed statistical significance for "presence of carious lesion" ( $p<0.05)$. Significant correlations between similar dimensions of the OHIP-49 and the SF-36 were also identified $(\mathrm{p}<0.05)$. In the present sample, the Portuguese version of the OHIP-49 presented results similar to those found in the literature and proved to be a reproducible and valid parameter for evaluating the impact of oral conditions on the quality of life of Brazilians.
\end{abstract}

DESCRIPTORS: Oral health; Quality of life; Validation studies.

\begin{abstract}
RESUMO: O objetivo deste estudo é desenvolver uma versão na língua portuguesa do OHIP-49 para ser utilizado no Brasil. A metodologia utilizada consiste de tradução, tradução de volta e revisão da tradução inicial, adaptação cultural e avaliação das propriedades de medida. O questionário foi aplicado, por meio de entrevistas, em brasileiros com 60 ou mais anos. Utilizou-se o coeficiente de correlação Kendall-tau para testar reprodutibilidade, coeficiente $\alpha$ de Cronbach para consistência interna e testes de Kruskal-Wallis e Mann-Whitney para validação. A reprodutibilidade demonstrou ser estatisticamente significante, com os coeficientes variando de 0,72 a 0,74 , entre as dimensões de três entrevistas. Os coeficientes $\alpha$ de Cronbach foram iguais a 0,96 e 0,90, para as dimensões das entrevistas e para o total de itens, respectivamente. A validade construtiva, demonstrada pela comparação das dimensões do questionário com os parâmetros clínicos apresentou-se estatisticamente significante para "presença de lesão cariosa" ( $<<0,05)$. Foram identificadas correlações significantes entre dimensões similares do OHIP-49 e do SF-36 ( $\mathrm{p}<0,05)$. Nesta amostra, a versão em português do OHIP-49 apresentou resultados semelhantes aos da literatura, demonstrou ser um parâmetro reprodutivel e válido para avaliar impactos das condições bucais na qualidade de vida de brasileiros.
\end{abstract}

DESCRITORES: Saúde bucal; Qualidade de vida; Estudos de validação.

\section{INTRODUCTION}

Until recent decades, oral epidemiology has used clinical indicators within a normative system for determining therapeutic needs. However, these indicators have been shown to be limited ${ }^{10,13}$, since they do not measure oral health multidimensionally.
The scientific community is beginning to concern itself with the correlation between oral health conditions and quality of life. Various instruments have been developed in order to identify and evaluate how oral problems interfere in people's daily lives, influencing their quality of life ${ }^{15}$. Most ques-

\footnotetext{
* Master of Science in Epidemiology, Professor, Department of Dentistry, Montes Claros State University.

** Professor, Department of Medicine, Federal University of São Paulo.

*** PhD in Epidemiology, Professor, Newton Paiva University Center.
} 
Pires CPAB, Ferraz MB, Abreu MHNG. Translation into Brazilian portuguese, cultural adaptation and validation of the oral health impact profile (ohip-49). Braz Oral Res 2006;20(3):263-8.

tionnaires have been produced and validated in English-speaking countries, although interest in developing their own measurement instruments has arisen in other countries. The instrument Oral Health Impact Profile (OHIP-14), a reduced version of the OHIP-49, was validated in a study involving pregnant women which was carried out at a Public Maternity in Rio de Janeiro ${ }^{5,6}$. However, the authors of these works reinforce that the sample used was not representative of the Brazilian population and, considering the vast Brazilian cultural diversity, the questionnaire must be tested before the beginning of the study. Beyond this aspect, when elderly populations are studied, it is important to use instruments which include specific questions about edentulism, such as the OHIP-491,14. Thus, it is still necessary to study the reliability and validity of the instrument OHIP-49 - one of the most widely used socio-dental indicators in English-speaking countries ${ }^{12}$ - in other Brazilian populations, especially the elderly, considering the need of evaluating dimensions which were eliminated from the instrument OHIP-14.

The objective of the present study is to translate the Oral Health Impact Profile (OHIP-49) questionnaire into Portuguese, to make the necessary cultural adaptations and to evaluate its measurement properties considering its inter- and intrainterviewer reproducibility and validity.

\section{MATERIAL AND METHODS}

The 49-question instrument chosen was developed by Slade, Spencer ${ }^{15}$ (1994). Questions are organized in seven conceptual impact dimensions: "functional limitations", "physical pain", "psychological discomfort", "physical disability", "psychological disability", "social disability" and "handicap".

The sample totalized 60 individuals of the Silver Age Program at Montes Claros State University. Sixty year-old people and older of both sexes were included. Individuals were not institutionalized and presented various educational levels. Selection of this age bracket was based on the fact that in Brazil it is the key age that reveals most of the clinical parameters used for the validation of this instrument.

There was a meeting with the participants of the study in order to clarify the objective of the study, its methodology and participant rights. After the meeting, an informed consent form was obtained from sample participants.
Firstly, a permission from the author was obtained to carry out the translation. After that, the research project was submitted to and approved by the Committee of Ethics on Research, Federal University of São Paulo.

The translation process from the original English OHIP-49 version was conducted following procedures recommended by Falcão ${ }^{7}$ (1999). It was necessary to adapt the translation considering the local culture in order to ensure semantic, conceptual, experiential and idiomatic equivalence.

The first translation into Portuguese was carried out by a dentist fluent in English and Portuguese. A conceptual, non-literal translation was emphasized. Then a translation back into English was done by a North American dentist. The two versions were compared by two translators and sentences were rewritten until consensus was reached. Special attention was given to verb tenses and colloquial expressions.

After this stage, a cultural adaptation phase was conducted involving a group of two dentists, dental school professors specialized in Public/Collective Health with knowledge about socio-dental indicators, a formally instructed patient and a North American professor. The research coordinator presented types and examples of cultural equivalence, so the group could revise the questionnaire, replacing problematic items by culturally accepted ones.

To evaluate the language used in the instrument and the structure adaptation, the questionnaire was applied in a pre-test to 10 people selected randomly from the sample. Some items were adjusted to clarify questions resulting in the final version of the Portuguese OHIP-49.

In order to standardize interviews, interviewers were trained and then a pilot test was used involving the same sample group.

The reproducibility of the Portuguese version of the OHIP-49 was assessed in three interviews applied by two interviewers to the remaining 50 people. Two interviews were carried out independently by interviewers 1 and 2 on the same day. After 15 days, a third interview was applied by interviewer 1 . Internal consistency and validity were also verified for the Portuguese OHIP-49 using the first interview from interviewer 1 .

For validity, average scores from the first interview were compared between groups with different clinical oral parameters such as: presence or absence of carious lesions (considering only cavitous lesions), presence or absence of removable prosthe- 
Pires CPAB, Ferraz MB, Abreu MHNG. Translation into Brazilian portuguese, cultural adaptation and validation of the oral health impact profile (ohip-49). Braz Oral Res 2006;20(3):263-8.

sis (total or partial) and number of missing teeth. These parameters were all evaluated at the first OHIP-49 interview carried out by interviewer 1 .

Participants were examined at the Dental Clinics, Montes Claros State University, Brazil, under artificial light using a mirror and a tongue depressor. Teeth were kept clean and dry to reveal alterations.

Besides the clinical parameters mentioned above, results obtained by the OHIP-49 dimensions during interview 1 were also compared with the results of the dimensions of the generic SF- $36^{4}$. This is a questionnaire with 36 items categorized into eight dimensions: "functional capacity", "physical aspects", "pain", "general state of health", "vitality", "social aspects", "emotional aspects" and "mental health". This questionnaire was applied together with the OHIP-49 in the first interview.

Inter- and intra-interviewer reproducibility was assessed by the Kendall-tau b correlation coefficient. The Mann-Whitney U and Kruskal-Wallis tests were used to compare values obtained in the OHIP-49 dimensions. The described clinical conditions and the internal consistency of the Portuguese OHIP-49 were evaluated with Cronbach's $\alpha$ coefficient. To correlate OHIP-49 and SF-36 dimension results, Spearman's correlation coefficient $\left(r_{s}\right)$ was employed.

\section{RESULTS}

After the process of formal translation and cultural adaptation was completed, two questions were still altered in the pre-test phase. In question 3: "Have you noticed a tooth which doesn't look right?", a "does not apply" option was added. There were people who had neither dentures nor their own teeth among the interviewed. In question 16: "Have you had painful spots in your mouth?", it was necessary to change the text to "Have you had any painful spots or area in your mouth?" because the word "spots" ("pontos", in portuguese) in the previous version was mistaken for "suture stitches".

Reproducibility, internal consistency and validity were assessed in a sample of elderly individuals ranging from 60 to 82 years old. A total of $52 \%$ of them lived on the periphery of Montes Claros and $48 \%$ lived in the central region of the city. Educational level varied from illiterate to university. Among the clinical conditions presented, $44 \%$ were toothless and $20 \%$ of those with teeth had caries (Table 1).
The Kendall-tau b correlation coefficient showed high reproducibility among the dimensions of the three Portuguese OHIP-49 interviews. Results varied from 0.72 to 0.74 ( $\mathrm{p} \leq 0.0001$ ).

Internal consistency was estimated by dimension between interviews and between items in the Portuguese OHIP-49 obtained in the first interview. Cronbach's $\alpha$ coefficient between interview dimensions indicates almost perfect consistency (0.963) as shown in Table 2. A similar result was

TABLE 1 - Clinical Characteristics of the Elderly Belonging to the Study Sample, Montes Claros, 2003.

\begin{tabular}{|c|c|c|c|}
\hline Characteristic & Conditions & Percentage & $\mathrm{N}$ \\
\hline \multirow{2}{*}{ Dental Situation } & Teeth & $56 \%$ & \multirow{2}{*}{50} \\
\hline & Toothless & $44 \%$ & \\
\hline \multirow{2}{*}{ Carious Lesion } & Present & $20 \%$ & \multirow{2}{*}{50} \\
\hline & Absent & $80 \%$ & \\
\hline \multirow{2}{*}{ Use of Prosthesis } & Yes & $70 \%$ & \multirow{2}{*}{50} \\
\hline & No & $30 \%$ & \\
\hline \multirow{6}{*}{$\begin{array}{l}\text { Number of } \\
\text { Missing Teeth }\end{array}$} & 0 to 4 & $12 \%$ & \multirow{6}{*}{50} \\
\hline & 5 to 10 & $6 \%$ & \\
\hline & 11 to 19 & $14 \%$ & \\
\hline & 20 to 27 & $16 \%$ & \\
\hline & 28 to 31 & $8 \%$ & \\
\hline & 32 & $44 \%$ & \\
\hline
\end{tabular}

$\mathrm{N}=$ number of examined individuals.

TABLE 2 - Internal Consistency between OHIP-49 dimensions for three interviews, Montes Claros, 2003.

\begin{tabular}{l|c|c|c}
\hline \multirow{2}{*}{ Dimension } & \multirow{2}{*}{$\begin{array}{c}\text { Cronbach } \\
\text { Alpha* }\end{array}$} & $\begin{array}{c}\text { Lower } \\
\text { Limit }\end{array}$ & $\begin{array}{c}\text { Upper } \\
\text { Limit }\end{array}$ \\
\cline { 3 - 4 } $\begin{array}{l}\text { Functional } \\
\text { Limitation }\end{array}$ & 0.953 & 0.925 & 0.972 \\
\hline $\begin{array}{l}\text { Physical } \\
\text { Pain }\end{array}$ & 0.945 & 0.912 & 0.967 \\
\hline $\begin{array}{l}\text { Psychological } \\
\text { Discomfort }\end{array}$ & 0.950 & 0.920 & 0.970 \\
\hline $\begin{array}{l}\text { Physical } \\
\text { Disability }\end{array}$ & 0.934 & 0.894 & 0.960 \\
\hline $\begin{array}{l}\text { Psychological } \\
\text { Disability }\end{array}$ & 0.916 & 0.865 & 0.949 \\
\hline $\begin{array}{l}\text { Social } \\
\text { Disability }\end{array}$ & 0.894 & 0.831 & 0.937 \\
\hline Handicap & 0.942 & 0.907 & 0.965 \\
\hline All Together & 0.963 & 0.941 & 0.978 \\
\hline \hline
\end{tabular}

*Cronbach Alpha: average measure of intra-class correlation. 
Pires CPAB, Ferraz MB, Abreu MHNG. Translation into Brazilian portuguese, cultural adaptation and validation of the oral health impact profile (ohip-49). Braz Oral Res 2006;20(3):263-8.

TABLE 3 - Scores for OHIP-49 dimensions in interview 1, Montes Claros, 2003.

\begin{tabular}{l|c|c|c|c|c|c}
\hline \hline & Average & Standard Deviation & Minimum & Median & Maximum & N valid \\
\hline Functional Limitation & 6.94 & 5.38 & 0 & 6 & 26 & 50 \\
\hline Physical Pain & 5.14 & 4.86 & 0 & 4 & 20 & 50 \\
\hline Psychological Discomfort & 3.28 & 4.02 & 0 & 2 & 18 & 50 \\
\hline Physical Disability & 3.94 & 4.22 & 0 & 2 & 15 & 50 \\
\hline Psychological Disability & 1.38 & 2.37 & 0 & 0 & 10 & 50 \\
\hline Social Disability & 0.42 & 1.34 & 0 & 0 & 8 & 50 \\
\hline Handicap & 0.46 & 1.34 & 0 & 0 & 6 & 50 \\
\hline Total Score & 21.56 & 17.18 & 3 & 16 & 70 & 50 \\
\hline \hline
\end{tabular}

obtained among the questionnaire's groups of dimension component items (0.910) showing high consistency.

Scores obtained for the OHIP-49 dimensions in the first interview (Table 3) were compared, considering sex, residence area and educational level. Mann-Whitney U tests showed no statistically significant difference between men and women for most of the dimension scores of the questionnaire. There was a statistically significant difference in the "psychological disability" ( $p=0.008)$, "functional limitation" ( $p=0.048)$ and "handicap" $(p=0.049)$ dimensions, where men showed greater impact than women. Concerning residence area, the greatest impact of oral conditions on quality of life is related to residents of the periphery of the city. There was a statistically significant difference in the "psychological discomfort" $(p=0.017)$ and "physical disability" $(p=0.031)$. There was no statistically significant difference regarding level of education.

In the validation process, the Mann-Whitney $\mathrm{U}$ test showed a statistically significant difference between the scores for the OHIP-49 dimensions and carious lesions. Scores related to these dimensions were higher among those with carious lesions, indicating a greater restrictive impact on the quality of life. This difference was statistically significant for the "functional limitation" $(p=0.003)$, "psychological discomfort" $(p=0.000)$ and "psychological disability" $(\mathrm{p}=0.000)$ dimensions.

Comparing dimension scores and the "presence or absence of prostheses" clinical condition, the Mann-Whitney U test revealed no statistically significant difference.

Missing teeth, among the dentate group $(\mathrm{n}=28)$, was registered considering number of missing teeth brackets: from 0 to 4 , from 5 to 10 , from 11 to 19 , from 20 to 27 and from 28 to 31 . Dimension scores were not statistically significant between these five brackets.

Spearman's correlation coefficient between dimension scores of the first-interview Portuguese OHIP-49 and dimension scores of the SF $=36$ showed statistically significant correlations. Correlations were found between the dimensions "functional limitation" and "general clinical condition" $\left(r_{s}=0.45\right)$, "functional limitation" and "functional ability" $\left(r_{s}=-0.28\right)$, "functional limitation" and "physical aspects" $\left(r_{\mathrm{s}}=-0.28\right)$ "functional limitation" and "pain" $\left(r_{s}=0.35\right)$, "physical pain" and "physical aspects" $\left(\mathrm{r}_{\mathrm{s}}=-0.31\right)$, "psychological discomfort" and "vitality" ( $\left.\mathrm{r}_{\mathrm{s}}=-0.33\right)$, "physical disability" and "functional ability" $\left(\mathrm{r}_{\mathrm{s}}=-0.38\right)$ with $\mathrm{p} \leq 0.05$.

\section{DISCUSSION}

There are some limitations in the present research, considering that it was carried out in a specific region of the country which presents a vast cultural diversity and diversity of social values. In spite of this, the national literature is poor in the use of studies with similar methods. Validation of the OHIP-14 was done in Brazil including only a group of pregnant women who had had their babies delivered at a Public Maternity in Rio de Janeiro $^{5,6}$. Thus, as previously mentioned, considering Brazil's vast cultural diversity and the need for applying the current questionnaire among the elderly population, it is important to validate the OHIP-49. Therefore, the results of the present study increase the utility of this questionnaire to Brazilian populations.

In its original English version ${ }^{15}$, when the OHIP-49 was compared with clinical parameters, particularly oral conditions, the results varied from 
Pires CPAB, Ferraz MB, Abreu MHNG. Translation into Brazilian portuguese, cultural adaptation and validation of the oral health impact profile (ohip-49). Braz Oral Res 2006;20(3):263-8.

culture to culture according to socio-economic conditions and access to health services.

In the present study, the questionnaire was applied as an interview considering the socio-cultural heterogeneity of the sample, which included illiterate people. This criterion was also used by the authors of the questionnaire in various other studies $^{15,16}$ as a result of the level of literacy of sample members, the methods and associations of other variables of interest in each study.

Response reproducibility among the three interviews conducted with the Portuguese OHIP-49 was within the parameters obtained with the original questionnaire, where correlation coefficients ranged from 0.42 to $0.74^{15}$.

Internal consistency estimated by dimension between interviews by the Cronbach $\alpha$ coefficient varied as expected between 0.89 and 0.95 , which is considered almost a perfect consistency. The values were higher than those obtained in the study carried out by Slade, Spencer ${ }^{15}$ (1994). Slade et al. ${ }^{16}$ (1996) demonstrated that these coefficients were similar to those of the Portuguese version.

Internal consistency among all of the dimension component items in the Portuguese OHIP-49 was virtually perfect, with a Cronbach $\alpha$ coefficient of 0.910 , which was similar to the result found by Slade et al. ${ }^{16}$ (1996).

Liddell, Locker ${ }^{9}$ (1997) showed that painful experiences are more important for men than women, and that pain intolerance was a significant predictor of anxiety for men. Men interviewed with the Portuguese OHIP-49 presented higher "functional limitation", "psychological disability" and "handicap" measures than women, confirming those findings in others studies.

Comparing scores in Portuguese OHIP-49 questionnaire responses between individuals with or without carious lesions, an anticipated statistically significant difference was found between those with and those without these lesions, with higher scores among those with lesions as in international studies. In comparing clinical oral conditions and the impact obtained with the OHIP-49, Broder et al. ${ }^{3}$ (2000) observed that individuals with higher caries indices related greater restrictions, which was also shown in the present study when more restriction was presented in the "functional limitation" dimension.

Slade et al. ${ }^{16}$ (1996) also identified individuals with dental caries showing the highest scores that were associated with the greatest impact. No statistically significant difference was observed between the average scores of prosthesis users and non-users. This same result appeared in the Portuguese OHIP-49.

Locker, Slade ${ }^{11}$ (1994) found that some individuals who had few missing teeth had higher OHIP-49 scores than those who had several missing teeth. A similar result was not found in the present study. This result suggests that the impact of oral health on the quality of life is influenced by culture.

In the present study, the impact observed on oral conditions was equivalent to that in other countries, interfering in the individuals' quality of life according to cultural values, structures, expectations and preferences.

The relationship between oral health and general health is not clear for most people. A study done in Canada showed that $70 \%$ of the population do not know that good oral health can mean better levels of general health ${ }^{8}$.

As in others studies ${ }^{2,3}$, no statistically significant difference was observed between clinical oral conditions and the results of the generic SF-36 questionnaire. This finding reveals the specificity of the OHIP-49, since it is designed to measure the effects of oral problems on the quality of life.

As in Broder et al. ${ }^{3}$ (2000), this study showed statistically significant correlations between results obtained in the simultaneous application of the OHIP-49 and SF-36 in Portuguese. The highest correlation observed suggests that those dimensions represent important issues in the individuals of the study sample.

\section{CONCLUSION}

The Portuguese version of the OHIP-49, adapted to the Brazilian culture, was presented in a simple and easy language that could be understood by individuals from any socio-cultural level. The demonstration of its reproducibility, reliability and validity makes this instrument an additional useful parameter for the evaluation of the impact of oral health on the quality of life of Brazilians, both in a research or in a health care institution. The Portuguese version of the OHIP-49 multidimensionally evaluated the impact of oral conditions on the quality of life of the participants in this study and is available for use in Brazil. 
Pires CPAB, Ferraz MB, Abreu MHNG. Translation into Brazilian portuguese, cultural adaptation and validation of the oral health impact profile (ohip-49). Braz Oral Res 2006;20(3):263-8.

\section{REFERENCES}

1. Allen PF, McMillan AS. The impact of tooth loss in a denture wearing population using the Oral Health Impact Profile. Community Dent Health 1999;16(2):176-80.

2. Allen PF, McMillan AS, Walshae D, Locker D. A comparison of the validity of generic- and disease-specific measures in the assessment of oral health-related quality of life. Community Dent Oral Epidemiol 1999;27(5):344-52.

3. Broder HL, Slade G, Caine R, Reisine S. Perceived Impact of Oral Health Conditions Among Minority Adolescents. J Public Health Dent 2000;60(3):189-91.

4. Ciconelli RM. Tradução para o português e validação do questionário genérico de avaliação de qualidade de vida "medical outcomes study 36-Item short form health survey (SF-36)" [Tese de Doutorado]. São Paulo: Escola Paulista de Medicina da UNIFESP; 1997.

5. De Oliveira BH. Prevalência e impacto da dor de dente em uma população de mulheres grávidas no Rio de Janeiro, Brasil [Tese de Doutorado]. Rio de Janeiro: Instituto de Medicina Social da UERJ; 2003.

6. De Oliveira BH, Nadanovsky P. Psycometric properties of the Brazilian version of the Oral Health Impact Profile-short form. Community Dent Oral Epidemiol 2005;33(4):30714.

7. Falcão DM. Processo de tradução e adaptação cultural de questionários de qualidade de vida: avaliação de sua metodologia [Dissertação de Mestrado]. São Paulo: Escola Paulista de Medicina da UNIFESP; 1999.
8. Health and Welfare Canada. Canada's Health Promotion Survey, 1990. Technical Report. Ottawa: Ministry of Supply and Services Canada; 1993. Catalogue H39-263/2-190E.

9. Liddell A, Locker D. Gender and age differences in attitudes to dental pain and dental control. Community Dent Oral Epidemiol 1997;25(4):314-8.

10. Locker D, Miller Y. Evaluation of subjective oral health status indicators. J Public Health Dent 1994;54(3):16776.

11. Locker D, Slade G. Association between clinical oral subjective indicators of oral health status in an older population. Gerodontology 1994;11(2):108-14.

12. Marcenes W, Bönecker MJS. Aspectos epidemiológicos e sociais das doenças bucais. In: Buischi IP. Promoção de saúde bucal na clínica odontológica. São Paulo: Artes Médicas; 2000. p. 74-98.

13. Pinto VG. Saúde bucal coletiva. $4^{a}$ ed. São Paulo: Santos; 2000.

14. Slade GD. Derivation and validation of a short-form oral health impact profile. Community Dent Oral Epidemiol 1997;25(4):284-90.

15. Slade GD, Spencer AJ. Development and evaluation of the oral health impact profile. Community Dent Health 1994;11(1):3-11.

16. Slade GD, Spencer AJ, Locker D, Hunt RJ, Strauss KP, Beck JD. Variations in the social impact of oral conditions among older adults in South Australia, Ontario, and North Carolina. J Dent Res 1996;75(7):1439-50. 